Pyrénées was felt strongly (M.M. intensity 7) at Beaudéon and with lesser intensity at other places near by.

During February the following earthquakes and earth tremors were felt : on the 22 nd of the month at Stoss in Mittelwallis (M.M. intensity 5); on the 25th in the Iles Ithoque and Leucade (M.M. intensity 4 ) ; on the 26th with slight damage at Ventura, California; and on the 28th, as already mentioned, off the north coast of Hokkaido, Japan. During March earthquakes were felt at the following places : on the 7th at Ilo-Ilo in the Philippine Islands; and on the 8th at Coblenz, Bonn, Cologne, Andernach and in the Ahr Valley. The earthquake of March 7 occurred at 02h. 07m. 46s., G.M.T., from a focus having an epicentre at lat. $10^{\circ} \mathrm{N}$., long. $124^{\circ} \mathrm{E}$. ; it had instrumental magnitude $6 \frac{3}{4}$.

Collective reports have been received from the central stations at. Strasbourg, Washington, D.C. (United States Coast and Geodetic Survey) and Zurich; and individual reports from the observatories at Belgrade, Cleveland (Ohio), De Bilt, Durham, Kew, Pasadena, Perth (Western Australia), Stuttgart, Toledo and Trieste.

\section{PREPARATION OF SPECIMENS FOR THE ELECTRON MICROSCOPE}

\footnotetext{
$\mathrm{T}$
} HE primary physical advantage of the electron microscope lies in its greatly increased resolving power, as compared with other forms of microscopy. Hence it finds a place as a research tool, supple. mentary to optical methods, in all those fields of investigation and routine testing which involve the examination of details smaller than a micron in extension. In the ten years or so since it became generally available, it has found innumerable applications. There are now about five hundred instruments in use throughout the world, in a variety of laboratories, but mainly in those engaged in biological and metallurgical research. A correspondingly wide variety of preparative techniques has been devised, and these must meet the special limitations imposed by the low penetration of electrons in matter and the consequent necessity of using specimens rather less than the wave-length of light in thickness and of desiccating them before observation. Great advances have been made since the Second World War, especially in the cutting of very thin sections of biological material and in preparing replicas of massive specimens, such as metals.

Until now, no collected account has been available of these techniques of electron microscopy, although there have appeared several works on the instrument itself. The omission has been due partly to the difficulty of treating a subject which is in rapid development, and partly to the great breadth of field to be covered. The need for such a compilation was discussed by the Electron Microscopy Group in 1945 , and on the proposal of Sir Charles Darwin it was decided to initiate a collective effort towards its production. Dr. D. G. Drummond, of the Shirley Institute, Manchester, was entrusted with the task of editing it. The co-operation of the chief laboratories in Great Britain engaged in electron microscopy was readily obtained, and it was possible to circulate a typescript draft for criticism by the end of 1947 .
It was used in the summer schools in the subject held in the Cavendish Laboratory, Cambridge, in 1948 and 1949, and benefited from this 'pilot run' as well as contributing greatly to the success of the courses. The editor then prepared an enlarged and amended version, which has now been published as the March issue of the Journal of the Royal Microscopical Society*, an arrangement which has permitted a high standard of production at a moderate cost. The editor and Society are to be congratulated on the appearance as well as on the content of the monograph in its final form.

Systematic treatment is accorded to the techniques which are basic to most applications of the electron microscope, followed by detailed attention to individual special fields : small particles, micro-organisms, surface replicas, tissues, sectioning and staining. There is also a short consideration of the most important instrumental matters : the determination of magnification and resolving power, and photography. The text is thus obviously of the greatest value to users of the instrument, but it will also be of interest to the non-specialist, in showing what is now possible of examination. For example, replica methods are now applicable not only to metals, but also to the surfaces of ceramic materials, porous materials such as wood, biological tissues, and crystals, including those of proteins. Similar progress has been made in the cutting of biological sections sufficiently thin (0.1-0.2 micron) for electron microscopy, through refinement of the existing types of microtome and attention to embedding-materials and cutting-temperature.

The scope of the book is confined to preparative methods and related techniques. It does not attempt to deal with the operation and maintenance of the electron microscope, a subject on which there is at present no manual. Nor is it concerned with the range and significance of the researches so far carried out with it. However, these aspects are well discussed in the "Symposium on Metallurgical Applications of the Electron Microscope" (Monograph and Report Series No. 8, Institute of Metals) and in R. W. G. Wyckoff's "Electron Microscopy", which deals mainly with biological work.

In its chosen field, the new manual fulfils admir. ably an important gap. In addition, its appearance is significant in showing how far the increasing complexity and range of application of scientific techniques may be reduced to order and interpreted by collective effort. Such a work is and could only be produced by some form of co-operation-and a form which is rather different from the team-work which is now usual on large research projects. The activity of the Electron Microscopy Group has comprised the practical teaching of the subject in the summer school, which is to be repeated this year, as well as the compilation of "The Practice of Electron Microscopy"; a comprehensive bibliography has also been assembled, by similar collaborative methods, and will shortly be published. If it has to be said that the instrument itself was invented and perfected in Germany, and that the United States possesses the greatest number of them, it is yet creditable that Great Britain is foremost in the exposition of such a widely useful technique, which has extended the resolving power of optical methods almost to atomic dimensions. V. E. CosSLETT

- The Practice of Electron Microscopy. Edited by D. G. Drummond for the Electron Microscopy Group of the Institute of Physics. (London: Royal Microscopical Society, 1950.) 218. 